Cahiers

Balkaniques

\section{Cahiers balkaniques}

36-37 | 2008

L'image de la période ottomane dans les littératures balkaniques

\title{
Des millets aux nations
}

La construction d'identités nationales dans le roman TOI AUSSI, TU ES GREC ? de Vassilios Christopoulos

From millets to nations: the construction of national identities in the novel You too, are you Greek? by Vassilios Christopoulos

\section{Nicolas Pitsos}

\section{(2) OpenEdition}

\section{Journals}

Édition électronique

URL : https://journals.openedition.org/ceb/1575

DOI : $10.4000 /$ ceb. 1575

ISSN : 2261-4184

Éditeur

INALCO

Édition imprimée

Date de publication : 1 décembre 2008

Pagination : 329-353

ISBN : 978-2-85831-173-6

ISSN : 0290-7402

Référence électronique

Nicolas Pitsos, "Des millets aux nations », Cahiers balkaniques [En ligne], 36-37 | 2008, mis en ligne le 19 mai 2012, consulté le 06 juillet 2021. URL : http://journals.openedition.org/ceb/1575 ; DOI : https:// doi.org/10.4000/ceb.1575

Ce document a été généré automatiquement le 6 juillet 2021

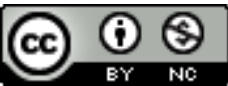

Cahiers balkaniques est mis à disposition selon les termes de la Licence Creative Commons Attribution - Pas d'Utilisation Commerciale 4.0 International. 


\title{
Des millets aux nations
}

La construction d'identités nationales dans le roman TOI AUSSI, TU ES GREC ? de Vassilios Christopoulos

From millets to nations: the construction of national identities in the novel You too, are you Greek? by Vassilios Christopoulos

\author{
Nicolas Pitsos
}

\section{Introduction}

1 Pendant les dernières années du XX et au début du XXI ${ }^{e}$ siècle, on relève, dans la littérature grecque, une profusion d'œuvres romanesques situant leur action à l'époque de l'Empire ottoman'1. Publié en 2005, le roman de Vassilis Christopoulos ${ }^{2}$, Toi aussi, tu es Grec ?3, participe de cette tendance littéraire. Sa trame est tissée autour de l'histoire de deux familles ${ }^{4}$, celle d'Anastassis et Lenoussio dans le vilayet de Monastir ${ }^{5}$, et celle de Christodoulos et Syméla dans le vilayet de Trabzon ${ }^{6}$, au tournant du XX siècle. Une troisième saga familiale, celle d'Alexis et Vanta Fourlis, se déroulant entre la Grèce et la Bulgarie, de la guerre civile grecque ${ }^{7}$ et à nos jours vient compléter la narration dans la dernière partie du roman. Les fils des deux premières familles transgresseront la loi ottomane. Le premier, Nicolios, s'en va avec Leggo qui fuit le harem du vali, et le deuxième, Lambo, se marie avec Hatouna, une Arménienne, or le firman impérial interdisait les mariages avec les membres de cette communauté de l'empire suite à leurs velléités séparatistes. Les destins des deux familles se croiseront à l'occasion du mariage de leurs enfants, Christodoulos et Nastassia. Le dernier lien entre les familles s'effectuera à Patras et aura comme acteurs, d'une part, Aïnout, l'arrière-petit-fils de Christodoulos et d'autre part, Valia, la fille d'Alexis, l'exilé de la guerre civile grecque.

2 Les événements, qui constituent le canevas historique sur lequel se dessinent les trajets des personnages du roman dans ses deux premières parties, sont les incidents de la Question d'Orient ${ }^{8}$, notamment de sa dernière phase: les propagandes nationalistes agissant en Macédoine ottomane, entre 1893 et $1903^{9}$; la révolution des Jeunes-Turcs ; les guerres balkaniques de 1912-13, avec leurs conséquences et surtout la partition, la 
nationalisation du territoire de la Macédoine ottomane et l'exode des mouhadjirs, c'està-dire, des populations musulmanes évincées de leurs terres dans les Balkans; la Première Guerre mondiale, la création d'un État éphémère arméno-pontique, les exactions subies par les communautés arménienne et Roum de l'Empire ottoman à la fin du XIXe et au début du XXe siècles, avec la mise en place de dispositifs coercitifs tels que les tekir kanunu (déplacements arbitraires) les amele tamburu (camps de travaux forcés), l'occupation de Smyrne par l'armée grecque, sa défaite par les combattants dirigés par Mustapha Kemal, et l'échange des populations entre la Grèce et la Turquie stipulé par le traité de Lausanne de $1923^{10}$. Les événements, qui délimitent l'horizon chronologique de l'action pendant la troisième partie, sont d'une part l'anamnèse de la guerre civile grecque et d'autre part des épisodes de la «nouvelle Question d'Orient »: le différend gréco-macédonien concernant l'appellation de la République de la Macédoine, les actions du mouvement séparatiste kurde et le destin tragique des immigrés clandestins à l'aube du XXI siècle.

3 Avant d'aborder l'analyse du roman proprement dit, j'aimerais émettre quelques suggestions concernant le statut des textes littéraires dans le travail d'historien, et formuler quelques considérations épistémologiques relatives aux rapports entretenus entre l'histoire et la littérature dans les courants historiographiques récents.

Dans ceux-ci, le principe novateur et fédérateur est l'idée selon laquelle toute histoire, quelle qu'elle soit, est toujours un récit mobilisant les mêmes techniques que les narrations imaginaires ${ }^{11}$. De ce constat largement accepté par les historiens inscrits dans le sillage de la New Cultural History ${ }^{12}$, certains, comme Hayden White, sont allés jusqu'à conclure à l'annulation de toute distinction entre fiction et histoire puisque celle-ci n'est qu'une fiction-making operation ${ }^{13}$. Ce relativisme bouleversant, déroutant et inquiétant, fut sévèrement critiqué par des historiens comme Carlo Ginzburg qui l'a désigné comme une machine de guerre sceptique qui refuse à l'histoire toute possibilité de dire la réalité qui fut et de séparer le vrai du faux ${ }^{14}$. Une thèse intermédiaire entre le rejet absolu des approches qualifiées de postmodernes et leur application aveugle fut défendue par Michel de Certeau dans son ouvrage, L'écriture de l'histoire quand il affirme que l'histoire est un discours qui met en œuvre des constructions, des compositions, des figures qui sont celles de toute écriture narrative, mais qui en même temps, produit un corps d'énoncés "scientifiques" si on entend par là la possibilité d'établir un ensemble de règles permettant de contrôler des opérations proportionnées à la production d'objets déterminés ${ }^{15}$.

5 D'autre part, en ce qui concerne la place de la littérature dans l'histoire, la lecture d'un roman historique peut interpeller l'historien et nourrir sa réflexion de plusieurs manières. Il peut adopter une posture critique et scruter la véracité des événements rapportés et relatés, repérer les discordances ou les décalages entre le temps narratif et le temps historique. Il peut également s'intéresser aux représentations véhiculées à travers l'acte diégétique.

Dans une typologie des rapports entre la recherche historique et le document littéraire, on pourrait envisager les cas suivants : le roman historique est contemporain de la trame: dans ce cas-là, je le considère comme un document valable à côté d'autres sources historiques pour la reconstitution d'un passé (notamment de tout ce qui est représentation collective). S'il est postérieur aux temps historiques décrits, mais l'auteur en a été témoin, je m'interroge sur les événements s'étant déroulés entre le moment du vécu servant d'inspiration à l'intrigue et sa mise en écriture, et enfin quand 
il est postérieur aux événements soutenant la trame et l'auteur n'en a pas été témoin, il a une valeur pour l'histoire de la réception d'un événement, de la perception mentale d'une époque par l'écrivain qui s'y exprime et nous transmet à travers les actes et les dires de ses personnages, sa vision de l'histoire narrée.

7 Dans le roman de Vassilis Christopoulos, Toi aussi, tu es Grec?, on rencontre au moins deux catégories de cette analyse. Sa première et deuxième partie se situent chronologiquement dans des périodes que l'auteur n'a pas vécues, les questions macédonienne et anatolienne entre 1893 et 1923, tandis que la troisième et dernière se réfèrent au temps présent et à des situations auxquelles il a assisté comme spectateur, à savoir, le différend gréco-macédonien, la question kurde et le destin des immigrés clandestins au tournant du XXI siècle. Ces temporalités historiques voient d'une part le passage d'une société impériale organisée autour du concept des millets ${ }^{16}$, ignorant la notion de la nation, à une société évoluant dans le cadre de l'État-nation et soudée autour de l'idéologie du nationalisme. La légitimité de cette structure politique, et surtout le modèle jacobin d'assimilation forcée et d'homogénéisation consacrée, est, à la fin $\mathrm{du} \mathrm{XX}^{\mathrm{e}}$ siècle, remise en question. Au sein des États-nations, de nouvelles exigences et de nouvelles sensibilités s'expriment, après avoir été occultées, réprimées et opprimées pendant longtemps. Comment les acteurs de ce roman (les personnages, mais aussi le narrateur) conçoivent-ils ce passage, comment se positionnent-ils face à l'idée de l'identité nationale et quelle est leur perception des événements ayant préparé, accompagnés et orchestrés un tel acheminement ? Enfin en quoi ce document textuel peut-il nous informer sur les lectures du passé et les compréhensions du présent dans la société grecque de nos jours?

\section{Les personnages du roman devant le phénomène de la nation}

\section{Définir la nation}

8 La question de la définition de la nation, de l'appartenance nationale des individus évoluant dans un système d'organisation sociale qui les ignore complètement, celui des millets de l'Empire ottoman, se trouve au cœur de cette œuvre romanesque. Elle est posée d'emblée et de front par un des protagonistes, le vieil Anastassis, habitant de Monastir et parfaitement intégré dans l'univers ottoman, quand il interroge Monsieur Béjart, agent de la propagande française en Macédoine et membre du comité philhellène français. Ce dernier lui répond que ce sera le modèle allemand fondé sur ce qu'il considère comme étant des critères scientifiques (l'histoire, la race, le sang), qui révélera aux individus, la nationalité à laquelle ils appartiennent. Il rajoute que ces critères, complétés par les paramètres de la parenté linguistique et la volonté de vivre ensemble, sont des arguments suffisants pour les Anglais et les Français afin de définir la nationalité de chacun ${ }^{17}$.

9 L'auteur introduit dans son roman un topos intellectuel récurrent, opposant deux conceptions antagonistes de la nation. L'une inspirée par le romantisme allemand et par la notion du volksgeist, et l'autre issue de la Révolution Française et de l'approche "rénanienne » de la nation comme un plébiscite permanent ${ }^{18}$. Et quand Anastassis ose demander ce qui se passera quand il n'y aura pas de tendance d'appartenance prépondérante dans une région, Monsieur Béjart lui rétorque que dans ce cas-là, ce 
sont les hommes de la science, les experts scientifiques qui doivent construire la nationalité ex nihilo: "les ethnologues, les géographes les historiens, les politiciens, seront les constructeurs de la nouvelle nationalité dominante ${ }^{19}$ ». Ce disant, Béjart exprime l'idée selon laquelle l'existence d'une nation relève d'un processus historiquement contingent, d'invention, de fabrication, de construction.

\section{Entre désignation «milletiste » et appellation nationale : le cas des Roums et des Grecs}

10 En ce qui concerne l'Empire ottoman, ce processus coïncide avec le passage des millets aux États-nations tout au long du XIX et au début du XXe siècle. Quant à la séquence de ce processus relative au passage du roum millet à la nation grecque, on assiste dans le roman, à une confrontation intéressante entre Christodoulos et son fils Lambo, représentant chacun une vision et une conception différentes de leur existence comme êtres politiques.

Lambo, s'adressant à son père, lui dit : « - Mon père, nous sommes des Grecs - Qui a dit ça mon fils ? - L'histoire, mon père - Qui t'a mis des idées pareilles en tête, mon fils ? Nous sommes des Roums, des Roums et des Yunan du Pont. La Grèce est loin mon fils. Même si l'histoire, c'est-à-dire les hommes, l'ont écrit ainsi, ils l'ont fait pour nous compliquer la vie..$^{20}$ ”

12 Il faut savoir que le terme Roum, transcription en turc ottoman du terme grec Romios, c'est-à-dire Romain, fut le qualificatif employé par les habitants de l'Empire romain d'Orient (autrement connu sous le nom d'Empire byzantin) pour se désigner euxmêmes. Cette appellation fut également attribuée à un des millets composant l'Empire ottoman après la disparition de l'Empire byzantin. Le sultan conquérant, Mehmet II, et ses successeurs immédiats, ont voulu regrouper au sein de la même communauté tous les chrétiens orthodoxes de leur empire. Parmi eux, il y avait à la fois des fidèles déjà rattachés au patriarcat de Constantinople, mais aussi des sujets ottomans appartenant autrefois à la juridiction des patriarcats des royaumes slaves, dont l'existence était compromise, une fois ces entités politiques dissolues et intégrées dans le giron de l'Empire ottoman ${ }^{21}$. En effet, le sultan Mehmet II, en reconnaissant comme seuls représentants de la communauté chrétienne de son empire et comme interlocuteurs du pouvoir central les Patriarches Roum et Arménien d'Istanbul, assura leur suprématie sur l'ensemble de ses sujets de confession chrétienne. Cette monopolisation du pouvoir spirituel fut contestée par la création du patriarcat de Peć (Ipek), en 1557, et par la création des patriarcats autonomes ou des églises autocéphales, qui tout au long du $\mathrm{XIX}^{\mathrm{e}}$ siècle $^{22}$ se sont détachés et affranchis de la tutelle institutionnelle du Patriarcat Roum d'Istanbul. Le mouvement de création d'États-nations, étant toujours accompagné de la mise en place d'une religion nationale, les sujets Roums de l'Empire deviennent la pomme de discorde entre les différentes propagandes nationales. Dans cette course à la conversion "aux religions nationales ", l'État grec essaiera tout au long de la Question d'Orient, de convaincre les Roums ottomans de leur appartenance à sa communauté nationale et il s'efforcera de les helléniser ou de leur inculquer une conscience nationale grecque. La divergence des propos tenus par les deux personnages du roman est également révélatrice de la prise de conscience de la part de l'auteur du désaccord qui aurait divisé les membres de cette communauté des Roums, au sujet de leur définition politique. 

il lui dit qu'à Kruševo, la ville où habite sa sœur, les Bulgares quand ils rencontrent un Grec, un Valaque, ou un Arvanite qui parle grec, se fâchent et lui demandent : «Vous Grecs, Roums, Valaques, Arvanites, êtes-vous tous devenus des Hellènes ${ }^{23} ? »^{24}$ marine qui l'ont arrêté à Patras suite au naufrage de son bateau qui l'emmenait en Grèce avec d'autres immigrés clandestins, ceux-ci lui répliquent d'un ton ironique et d'une manière insultante : « Dites donc, on est tombé sur un Hellène du Kurdistan, Vous tous, Albanais, Kurdes, Ukrainiens, vous êtes tous devenus des Hellènes, vous avez appris deux mots de grec et vous pensez que nous allons vous croire. ${ }^{25}$ »

En effet, dans le cadre des millets, le concept d'Hellène et d'hellénisme ${ }^{26}$ servit d'outil à une politique de prosélytisme, d'assimilation, d'identification massive à une certaine communauté imaginée, pour employer le terme de Benedikt Anderson ${ }^{27}$. En revanche, dans le cadre des États-nations, il acquiert un sens restreint, incitant à l'exclusion, au rejet de l'Autre, au refus d'appartenance d'un étranger à la communauté nationale, artificiellement constituée à l'intérieur des frontières de l'État-nation. Les paroles que l'auteur attribue à ces policiers dans le roman sont symptomatiques et révélatrices de l'esprit d'une société au sein de laquelle les manifestations racistes et xénophobes sont rampantes et la stigmatisation de l'Autre comme potentiellement dangereux, largement diffusée.

\section{Nationalistes versus « milletistes » et communautaristes}

Les personnages, qui peuplent le roman de Christopoulos, tant par leurs caractéristiques que par leurs actions, représentent plusieurs points de vue à l'égard du concept de la nation, et perçoivent de manière variable le sens ou le contenu de l'identité nationale. On pourrait classer leurs attitudes en deux grandes catégories, ceux qui optent pour la création d'un État-nation au détriment d'une entité impériale ou étatique déjà existante et ceux qui s'accommodent du statut de communauté culturelle et cultuelle distincte, respectée et reconnue, au sein de ces entités politiques. Les premiers semblent séduits par les sirènes du nationalisme, tandis que les autres raisonnent en termes de millets ou de communautés.

Maître Anastassis est l'archétype même des milletistes, de ceux qui conçoivent leur vie dans le cadre des millets, ces piliers de l'organisation sociale ottomane. Le narrateur nous apprend qu'il est caravanier à Monastir, et qu'il a toujours à côté de lui, la Bible et l'ouvrage de Rigas Ferraios sur la nouvelle administration politique des habitants de Roumélie, d'Asie Mineure, des îles de la Méditerranée et de la Moldovalachie ${ }^{28}$. Rigas avait élaboré à la fin du XVIII ${ }^{e}$ siècle, un modèle d'organisation politique, qui visait à remplacer l'Empire ottoman par un système de gouvernement libéralisé et démocratisé avec ses peuples fraternisés en vue de la construction d'une société imprégnée des principes du Siècle des Lumières et pétrie des idéaux de la Révolution Française. Quand on connaît la nature fédéraliste de ce projet élaboré par ce représentant de l'Aufklärung dans les Balkans ottomans, on peut également se rendre compte des idées politiques d'Anastassis. Quant aux Écritures saintes qu'il consulte très régulièrement et qu'il étudie assidûment, celles-ci le rattachent à une organisation religieuse de la société autour de la notion du millet, c'est-à-dire du regroupement des sujets de l'Empire ottoman sur la base de critères confessionnels. 
(a) Monsieur Béjart retrouve le vieil Anastassis après la Grande Guerre, il lui demande s'il est désormais prêt à vivre comme un Serbe en Serbie. Il lui répond affirmativement, car c'est là «mon lieu, ma fortune, ma famille ${ }^{29}$ ». Il s'agit d'une perception régionaliste de la notion de l'appartenance nationale qui vient s'ajouter à son approche traditionaliste en termes de millets, et fraternaliste en termes de fédération.

19 multiculturel de l'Empire ottoman d'avant l'expression des nationalismes et d'avant la création des États-nations. D'origine arvanito-valaque, elle parle, outre l'albanais et le valaque, le "romeika ", la version vernaculaire du grec parlé par les sujets roums de l'Empire ottoman, mais aussi le bulgare, le serbe et le macédonien local. Elle incarne à elle seule, la variété linguistique de la Macédoine ottomane et illustre bien le phénomène du multilinguisme dans la société des millets. Autres exemples de ce brassage linguistique ou plutôt de cette expression en plusieurs langues, c'est Leggo, la belle-fille de Lenoussio et Hatouna, l'Arménienne du vilayet de Trabzon. Leurs destins se rapprocheront à l'occasion du mariage de leurs enfants à Smyrne. Le narrateur nous apprend que, quand elles se sont rencontrées, elles ont très vite sympathisé et se sont mises à parler une espèce de langue hybride, leur romio-albano-valaquo-arménien ${ }^{30}$.

Nicolios, le fils d'Anastassis et Lenoussio, exprime, lui aussi sa répulsion vis-à-vis de l'idéologie nationaliste, quand il commente les événements tragiques se déroulant dans l'Empire ottoman pendant la Première Guerre mondiale. À cette occasion, il affirme que «les nationalismes réveillent les revendications nationales et ces revendications entraînent la violence étatique ${ }^{31}$ ». Son rattachement à l'idée des millets date de sa découverte, à Salonique, du sens des mots inscrits sur un pendentif (yordan) de Mevlana que la vieille Aïmé, Tsigane-Albanaise, lui avait confié un jour au han de la ville d'Elbasan. À cette occasion, il apprend que Mevlana Djelaleddin Roumi avait enseigné que Dieu était unique, malgré ses appellations différentes ${ }^{32}$ et qu'il avait conçu le rôle de la religion comme formateur de liens. Ainsi, s'initie-t-il au sens profond de l'universalité du message solidaire et fraternel des religions, en opposition flagrante avec les comportements de quelques prélats censés prêcher la vérité des doctrines religieuses et qui finissent par mettre leur prédication au service des propagandes nationales, par définition exclusivistes et antagonistes. C'est le cas du pope Kyriakos qui vient voir le vieil Anastassis, pour le convaincre de livrer son fils en fuite, aux autorités ottomanes. Ce pope n'est pas seulement méprisant vis-à-vis des langues liturgiques autres que le grec, "la seule langue que Dieu reconnaît ${ }^{33}$ ", mais il développe en plus des propos d'un fanatisme et d'une intolérance insensés envers les fidèles musulmans quand il affirme que la bien-aimée de Nicolios, en tant que musulmane, «est souillée ${ }^{34}$ ». Il avoue en même temps son soutien inconditionnel à la cause du nationalisme grec en déclarant que « les écoles grecques [...] sont la meilleure défense contre les propagandes bulgare et roumaine ${ }^{35}$ ». En revanche, son homologue dans le village du vilayet de Trabzon confesse à Anestis, le fils de Christodoulos que " c'est le microbe du nationalisme qui les a mis dans une position délicate et face à une situation dangereuse et non pas leur foi ${ }^{36} »$.

21 Une autre fidèle représentante du système des millets est Leggo, l'épouse de Nicolios. À la question de son mari, qui voulait savoir quelle était la nation à laquelle elle croyait appartenir, elle répond qu'elle fait partie du roum millet. 

qui, élevée dans l'admiration et la sublimation de la langue grecque, développera des réflexes nationalistes. À Smyrne, où sa famille ira s'installer, elle préférera fréquenter le Wiener Bank, car son directeur, Paris Taveloudis, vient de Grèce. Ce dernier, par contre, se considère plutôt comme Smyrniote et non plus comme Grec, et il fait partie de tous ceux qui croient que la mode des nationalismes portera atteinte et préjudice à l'Anatolie multiculturelle.

Autre adepte du milletisme, et d'une auto-définition en termes religieux, c'est

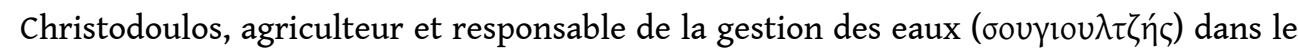
caza de Sourmena du vilayet de Trabzon. Avant de se coucher, « il se tourne vers l'icône qu'il a dans sa chambre et il fait le signe de croix en pensant que les temps sont difficiles et que les chrétiens doivent rester vigilants ${ }^{37} »$. Ce qui est important pour lui, c'est « de ne pas mettre sa vie et la vie de ceux qu'il aime en danger tout en gardant sa religion $^{38}$ ». Et à son fils qui se révolte contre les exactions qu'ils subissent de la part du vali et des autorités ottomanes, il répond que les Turcs eux aussi subissent le même sort : " les Turcs aussi, mon fils, ils font la même chose, eux aussi font des courbettes. Dans le monde entier, c'est comme ça que cela se passe. On a toujours quelqu'un audessus de notre tête, peu importe s'il est ottoman ou roum. On va dans son sens, et on a l'esprit tranquille et si on essaie de s'y opposer, on a des ennuis ${ }^{39}$ ». Dans une approche stoïque du fait social, mais aussi dans une compréhension de celui-ci en termes de rapports de force, indépendamment de l'identité nationale de ceux qui y participent, il affirme que l'injustice est inhérente au système de l'organisation sociale, et non pas à l'identité de l'appartenance confessionnelle ou nationale de ceux qui dirigent.

À côté des nationalistes idéologues, qui comme Lambo, le fils de Christodoulos, œuvrent pour l'éveil d'une conscience nationale chez leurs coreligionnaires, il y a aussi les nationalistes opportunistes comme le dignitaire ottoman Serge Zamanic qui cherchent à tirer profit à titre personnel de leur implication dans la promotion des différentes propagandes nationales. Au départ, consacré à la promotion des propagandes grecque et serbe à Monastir, comme nous renseigne le vieil Anastassis, « il a aussi et avant tout fait des affaires avec les Bulgares ${ }^{40} »$.

De son côté, le nationalisme turc est incarné par Kemal, le représentant du pouvoir ottoman dans le village de Lambo, dans le vilayet de Trabzon. Il affirme que «dans notre grande démocratie (suite à l'avènement au pouvoir des Jeunes-Turcs), il n'y aura plus ni musulmans, ni chrétiens. Il n'y aura plus d'Ottomans, ni de Roum raïas, ni de juifs, ni de Tchétchènes, ni de Circassiens, ni de Lazes, ni de Kurdes, Assyriens, Syriens ou Libanais. Il y aura seulement des citoyens égaux ». Mais il souligne que « les Roums et les Arméniens doivent, eux aussi oublier leurs nationalismes. La Grèce est loin et l'Arménie n'existe pas. ${ }^{41}$ " Ce disant, Kemal se fait le porte-parole d'une politique de «démilletisation» de l'Empire, voulue et promue par les Jeunes-Turcs, en vue du remplacement des différentes identités confessionnelles, par une identité laïque si possible d'une part, et suffisamment turquifiée d'autre part.

L'engagement militant au parti travailliste kurde, autrement connu sous le nom de PKK, d'Aïnout, le petit-fils d'Anestis, un Roum et de Dilan, une Kurde, semble indiquer que pour l'auteur cette politique de turquisation de l'Empire ottoman entamée par les Jeunes-Turcs et poursuivie dans le cadre de la République turque, après son établissement en 1923, ne soit pas encore achevée. Cependant, Aïnout, après avoir participé à la lutte armée menée par le PKK contre l'État turc, se dresse contre la 
création des nouveaux États-nations. Il explique à ses camarades de route, qui continuent à revendiquer un État kurde autonome, que l'époque des nationalismes est définitivement révolue. «Il s'agissait d'un phénomène historique du XIX ${ }^{\mathrm{e}}$ et des débuts $\mathrm{du} \mathrm{XX}^{\mathrm{e}}$ siècle qui n'est maintenu que dans des régions arriérées en engendrant des situations problématiques, au sein même des démocraties modernes, comme l'Albanie, la Serbie, la Grèce ou la Macédoine ${ }^{42}$. »

En dehors de la définition en termes nationaux ou de millets de l'individu, il y a aussi une approche alternative qui est exprimée dans le roman par Chryssanthos, le frère de Lambo, les ouvriers de tabac de Salonique ou Valia, la fille de l'exilé de la guerre civile grecque. Dans la fabrique de tabac, où Nicolios travaille pendant quelque temps après son arrivée à Salonique, les ouvriers parlent des nations et des religions. «Pour les uns c'était l'idée de la nation qui primait, pour d'autres l'idée de la religion prévalait, alors que les partisans du socialisme souriaient ${ }^{43}$ ». On sait qu'au début du XX $\mathrm{XX}^{\mathrm{e}}$ siècle, époque $\mathrm{du}$ séjour de Nicolios à Salonique, cette ville ottomane était un foyer très actif pour l'élaboration et la propagation d'idées socialistes grâce à des associations comme la Fédération ouvrière de Salonique fondée par Avraam Benaroya et ses camarades ${ }^{44}$. De son côté, Valia elle, a développé une philosophie de vie antinationaliste, voire même supranationale. Elle veut écrire "un livre qui minera à la fois les fondements du nationalisme, et l'idéologie de l'identité nationale permanente (...) qui mettra en avant l'idée selon laquelle, la patrie nationale peut être n'importe quel pays qui nous procure ce dont on a besoin pour vivre ${ }^{45}$ \%. Quant à Chryssanthos, en s'adressant à Christodoulos, son neveu, il lui dit qu'en tant que marin, sa patrie c'est la mer. Et il rajoute que "les nationalismes sont les affaires des habitants de la terre ferme ${ }^{46}$ ». Quand il débarque pour quelque temps à Smyrne, il crée un groupe de musique qui est le reflet parfait de la société multiculturelle qu'était cette ville au début du XXe siècle. Parmi les musiciens « il y avait Mosé, Juif ashkénaze de Pologne qui travaillait comme antiquaire et jouait de l'oud d'une manière magistrale [...] Syméon, le Sépharade, était virtuose du violon. Karabet l'Arménien jouait du santour, Ali, le Turc așik, qui avait travaillé dans le passé comme zeybek jouait du saz et Chryssanthos lui-même du taboura ${ }^{47}$.

28 Comme l'a pertinemment souligné Ernest Gellner, dans son ouvrage Nations and Nationalism ${ }^{48}$ l'hétérogénéité culturelle était la règle dans les empires, royaumes et principautés de l'ère prénationale. Les références identitaires des individus étaient déterminées par leur statut social, leur religion, leur appartenance à une communauté locale. La formation des identités nationales a consisté en un bouleversement total de ce système de référence. Comment les événements marquant ce passage, dans l'univers de l'Empire ottoman, sont-ils perçus par les personnages du roman?

\section{Les personnages du roman devant les événements historiques}

29 Les personnages, ainsi que le narrateur expriment leurs points de vue principalement face à quatre cycles historiques : les événements qui ont bouleversé et agité la région de la Macédoine ottomane entre 1893 et 1903, l'avènement et la consolidation au pouvoir de l'Empire ottoman des Jeunes-Turcs, les épisodes de la décennie sanglante de 1912-1922 et le renouveau de la question d'Orient avec le différend gréco-macédonien et la question kurde au tournant du $\mathrm{XX}^{\mathrm{e}}$ siècle. 


\section{Des millets aux nations en Macédoine et en Anatolie} rapport à ses interlocuteurs, représentants des propagandes nationales, et hérétiques à l'égard de l'orthodoxie politique des royaumes chrétiens entourant la Macédoine, au sujet du statut de la région de la Macédoine et de sa diversité culturelle, révèlent aux lecteurs des vérités qui contrastent avec les assertions du discours officiel de l'État grec actuel. Par exemple lorsqu'il s'agit du cas de la reconnaissance de l'existence du peuple macédonien habitant dans la région géographique de la Macédoine ottomane ou de la perception peu héroïque de l'action des propagandes nationales dans cette contrée de l'Empire ottoman à la fin du XIX et au début du XX $\mathrm{XX}^{\mathrm{e}}$ siècles.

Si les réflexions sur la question macédonienne du vieil Anastassis peuvent secouer le lecteur dans ses certitudes historiques nourries des légendes d'une mythologie nationale, les réactions des personnages face au régime des Jeunes-Turcs empruntent, au contraire, un schéma plus stéréotypé, simplifié et largement diffusé dans l'historiographie grecque contemporaine. À l'enthousiasme initial ou à l'accueil réservé, voire même réticent, des nouvelles de la révolution constitutionnelle, succèdent chez les personnages roums du roman, la désillusion, le désenchantement et 
la déception devant le règne de la terreur et la campagne d'intimidation dont ils sont victimes.

Le narrateur annonce au lecteur l'écho des événements du mois de juillet 1908, sous le retentissement des slogans, "vive la justice, vive la liberté ${ }^{53}$ ». Toujours selon le narrateur, la nouvelle constitution signifiera l'arrivée d'une nouvelle ère, synonyme de liberté et de droits égaux pour tous les habitants de l'Empire, indépendamment de l'appartenance ethnique, de la confession et sans antagonismes nationaux.

Les personnages les plus âgés, Christodoulos et Anastassis, se montrent assez incrédules à la sincérité des intentions du mouvement des Jeunes-Turcs. Le vieil Anastassis s'étonne que « les Jeunes-Turcs aient fait une révolution contre le sultan afin d'offrir en cadeau aux chrétiens des droits et des libertés ${ }^{54}$ ». Sur la même longueur d'onde et saisi de la même inquiétude devant les événements, "Christodoulos dit à Lambo que tout cela (tous ces discours libéraux et démocratiques) ressemble à un piège tendu par les Jeunes-Turcs afin qu'ils puissent repérer et éliminer tous ceux qui réagiront ${ }^{55}$ »

De l'autre côté, les représentants des nouvelles générations expriment leur approbation et leur soutien au changement gouvernemental. On apprend que Lambo connaissait le mouvement des Jeunes-Turcs et il était en faveur des réformes pour la justice, la liberté et la constitution, afin que tous les sujets de l'Empire deviennent égaux. ${ }^{56}$ Nicolios, pour sa part, est lui-même membre de ce mouvement politique. "Mais un soir de juillet 1909, alors qu'il rentrait chez lui, il est agressé par trois Turcs en tenue militaire. Il est amené dans une salle de tortures et il n'est sauvé que grâce au pendentif (yordan) de Mevlana qu'il portait ${ }^{57}$ ». Quelques jours plus tard, il lit « dans le journal grécophone, $L a$ Nouvelle Vérité, qui soutenait le mouvement des Jeunes-Turcs, un article de protestation dénonçant les persécutions contre les populations roums de l'Empire ${ }^{58}$ ».

Ibrahim, le compagnon fidèle de Nicolios, avoue que «tous ces incidents d'intimidation s'inscrivent dans une politique de turquisation des chrétiens de Macédoine, d'Asie Mineure, du Pont et d'Arménie et que s'il voulait se sauver, il devrait soit embrasser l'islam soit partir de Salonique et aller à Smyrne ou à Athènes ${ }^{59}$ ».

40 En ce qui concerne les conflits de la décennie 1912-1922 dans l'Empire ottoman, l'auteur accorde une place équitable, dans l'économie de son roman, aux drames des partis impliqués. Si le narrateur énumère les dispositifs de déportation forcée ou de réquisition arbitraire mis en œuvre par le régime ottoman pendant la Grande Guerre, il relate également le sort tragique des mouhadjirs, c'est-à-dire de toutes les populations musulmanes qui pendant les Guerres balkaniques ont été expulsées de leurs terres natales.

$41 \mathrm{Au}$ début de la Première Guerre mondiale, «de nombreux Arméniens et Roums partaient vers la Russie, l'Ukraine, la Grèce afin de ne pas être enrôlés. À peine les Roums s'en allaient-ils que les premiers mouhadjirs commençaient à arriver. Il s'agissait des réfugiés des Guerres balkaniques... ${ }^{60}$ » Le père d'Ibrahim est un de ces réfugiés.

Lors d'un dîner à la maison de Nicolios dans la ville de Smyrne occupée par l'armée grecque, la tension monte quand Christodoulos, son beau-fils, et Ibrahim, son compagnon de métier, expriment des idées divergentes vis-à-vis des conflits qui avaient agité l'Empire ottoman depuis les guerres balkaniques et jusqu'à la fin de la Grande Guerre. Ibrahim condamne les actes de violence visant les Roums de la région pontique. Mais en même temps, il rappelle que sa famille ainsi que d'autres familles 
musulmanes ont été, elles aussi victimes des vexations et exactions commises par les armées des royaumes chrétiens et il évoque l'existence de comités nationaux et l'expression de revendications séparatistes en vue de la création d'un Pont autonome et d'un État arménien, soutenues pendant la guerre par la Russie. Et devant cette situation, il se demande : «Que peut faire la Turquie ? Doit-elle souscrire à sa propre dissolution ? ${ }^{61}$ » À cette question rhétorique, Christodoulos répond en mettant en avant le principe d'autodétermination défendu par le président américain Wilson, au Congrès de Paris. Ibrahim conteste immédiatement la validité et l'efficacité de ce principe en rétorquant que dans la plupart des cas, il n'y a pas de régions avec des populations compactes et homogènes et en se servant de l'exemple de la Macédoine, il ajoute que "pendant les guerres balkaniques, les royaumes de Grèce, de Bulgarie et de Serbie se sont partagés entre eux les territoires de cette contrée ottomane en se les appropriant en fonction de l'ordre de leur conquête ${ }^{62} »$. Et, quand Christodoulos lui réplique qu'«en Macédoine il y eut un conflit armé tandis que dans la région du Pont l'Empire se bat contre des populations civiles", Ibrahim lui répond qu'" en Anatolie aussi l'armée ottomane s'oppose à des antartès équipés par la Russie, la Grèce et les puissances de l'Entente ${ }^{63} »$.

La composition et la configuration de la prise de parole, dans cet extrait de l'intrigue du roman, correspondent, à mon avis, à ce que Hayden White qualifia de "narrations concurrentes » qui peuvent être évaluées, critiquées et classées selon leur fidélité aux données factuelles. En ce sens, le conflit entre ces « narrations concurrentes " a moins à avoir avec les faits relatifs au sujet traité qu'avec les différentes significations qui sont assignées à ces faits par la mise en intrigue ${ }^{64}$. Dans notre cas des massacres perpétrés et des politiques d'extermination appliquées pendant la Première Guerre mondiale, dans la région de l'Anatolie, ce ne sont pas les faits qui sont remis en cause par les deux visions opposées, mais leurs causes et surtout les circonstances de leur déroulement. Pour Christodoulos, les tueries sont unilatérales et ont pour seule cible les populations civiles, tandis que pour Ibrahim, elles interviennent dans le cadre d'un conflit armé entre les autorités ottomanes et des groupes séparatistes.

Commentant le départ des populations roums d'Anatolie, au moment de l'échange des populations décidé par le traité de Lausanne, Hatouna, s'apitoie sur leur sort et fait allusion au destin tragique qui les attend en Grèce à cause de l'accueil défavorable qui leur sera réservé par les autorités et les populations locales. Pour elle, c'est la cause nationaliste défendue aussi par Lambo son mari, qui les a fait périr et qui a entraîné leur expulsion ${ }^{65}$.

\section{Les politiques de construction d'identité nationale dans les nouveaux États-nations}

Quant aux conséquences de tous ces traités imposant et traçant des nouvelles frontières suite aux confrontations militaires de cette période, le vieil Anastassis, s'adressant à Monsieur Béjart lui dit qu'« indépendamment du tracé des frontières (au sein de l'Empire ottoman) aucune nation, aucun État, même de petite taille, ne sera jamais homogène, et en plus, la plupart des "nationaux" resteront à l'extérieur de l'État dans lequel ils aspirent à s'intégrer ${ }^{66}$. » À cette remarque Monsieur Béjart répond que « dès que le nouvel État sera constitué et que son pouvoir sera consolidé, il pourra alors fabriquer sa nation à sa propre image ${ }^{67} 》$. 

les communautés ethnolinguistiques sont l'équivalent des millets. Les revendications séparatistes de certaines d'entre elles, en vue de la formation de nouvelles entités étatiques, représentent le pendant des oppositions aux Empires par les nationalistes du $\mathrm{XIX}^{\mathrm{e}}$ et $\mathrm{XX}^{\mathrm{e}}$ siècles. Suite à la question des millets nationalisés on pourrait ainsi évoquer le phénomène de nations milletisées ou en voie de milletisation.

51 Dans le roman, Aïnout, combattant et militant au sein du parti travailliste kurde qui réclame dans les années 1980 et 1990 la création d'un État kurde autonome, évolue vers une position partisane de l'intégrité territoriale des États existants, en l'occurrence de 
la Turquie et il s'oppose à ses compagnons qui veulent continuer à se battre pour la reconnaissance d'une entité politique kurde indépendante. Le changement de sa pensée politique et de son attitude nous est communiqué suite à la diffusion de la nouvelle politique du parti décidée à l'occasion de son $8^{e}$ congrès et avec son leader, Odjalan, déjà emprisonné. Les camarades d'Aïnout refusent de se plier aux nouvelles positions du parti. En revanche Aïnout se conforme à ce nouveau discours, et il pense que l'avenir de la nation kurde et son espoir pour une amélioration des conditions de vie de ses membres doivent s'accorder aux efforts pour la démocratisation et la libéralisation de l'État turc: « la nouvelle politique réaliste affirme donc, que nous nous battons pour les droits démocratiques et culturels du peuple kurde. Cette politique est capable de faire avancer la résolution démocratique de la question kurde, dans le cadre des États déjà existants $^{70}$ ». Il conçoit la nation en termes culturels et non pas politiques. Selon lui, la nationalisation politique d'une communauté nuit à sa cause et elle est également contraire aux idéaux humanistes.

Valia, chez qui Aïnout loge pendant quelque temps après son arrivée à Patras, en tant qu'immigré clandestin, parle de la question kurde avec lui. Elle comprend parfaitement bien la réaction de ses camarades face au changement de politique décidé par le PKK. Selon elle, « l'homme moyen est attaché à l'idée de la patrie nationale. Il a besoin de ses propres symboles nationaux ». Et elle lui cite comme exemple « l'hystérie collective qui a frappé les Grecs quand il y a dix ans, (l'action du roman dans cette troisième partie se déroule en 2002) un pays voisin employa le nom de Macédoine. Les Grecs considéraient ce nom comme leur héritage exclusif et leur possession ${ }^{71}$ ", lui explique Valia. Ces paroles, de la part d'un des personnages centraux du roman, nous montrent qu'une partie de la société grecque, celle qui s'exprime à travers la plume de l'auteur, a déjà pris ses distances avec le discours officiel énoncé par l'État grec dans cette question affaires diplomatique.

\section{Conclusion}

Des voix dissidentes à la propagande officielle, comme celle de Valia, ou d'autres personnages, qui tout au long du roman remettent en question la doctrine d'une seule interprétation et acceptation de l'événement historique, invalident les tentatives nationalistes de monopolisation du rôle de victime, et de l'expérience des situations traumatisantes. Ce faisant, ils placent cette œuvre parmi ce qu'on pourrait appeler le nouveau roman historique, par opposition au roman historique du XIX ${ }^{e}$ siècle, dont la formule narrative a été élaborée par Walter Scott (lui aussi inspiré, d'ailleurs, par une narration de l'Histoire selon les principes du romantisme en vogue à son époque) qui visait à participer à une pédagogie nationale, un apprentissage et une sublimation de la nation, en permettant à ses lecteurs de découvrir les grands épisodes de l'histoire nationale, ses anecdotes, sa galerie de héros. Le roman de Christopoulos retrace, à travers les événements qu'il raconte ainsi que par l'intermédiaire des interrogations et des confrontations dialogiques de ses personnages, le processus conflictuel de la mise en place d'une mythologie nationale, soucieuse de légitimer l'existence de l'État-nation et d'assurer son unité.

Dans cette perspective, la thématique qui régit la structure syntaxique de la narration, est à mon avis fondée dans ce roman sur la juxtaposition de destins entre individus à identité nationale, appartenance confessionnelle, expression linguistique, uniques, 
codifiées, figées et individus à définition nationale, culturelle et cultuelle multiple, malléable ou incertaine. L'auteur met en scène des trajectoires de migration vers une nouvelle terre (le cas de Nicolios) vers une nouvelle religion (le cas d'Anestis qui par amour pour Dilan embrasse l'islam) vers une nouvelle langue (le cas d'Alexis Fourlis, exilé de la guerre civile grecque en Bulgarie) Ce sont ces expériences que Valia, à l'instar de notre auteur, son alter ego en quelque sorte, a envie de mettre par écrit. Et le narrateur nous informe qu'« elle a déjà recueilli les témoignages d'individus qui ont laissé un pays pour un autre, qui ont oublié une langue pour une autre, qui ont changé de religion. Des histoires des réfugiés grecs de la guerre civile grecque devenus Bulgares, de Russes et d'Ukrainiens qui veulent devenir Allemands et se contentent de devenir Grecs, d'Albanais qui s'efforcent de devenir Grecs. ${ }^{72}$ » À l'aube du XXI ${ }^{e}$ siècle, les acteurs de déplacements subis, forcés, imposés par des conjonctures politiques, économiques, sociales et de déplacements volontaires, librement décidés, pour des raisons personnelles, sentimentales ou culturelles ne sont plus les sujets du passage des millets ottomans aux États nationaux, mais les immigrés et les réfugiés, victimes de confrontations civiles au sein de ces États-nations et à la recherche de nouvelles identités nationales.

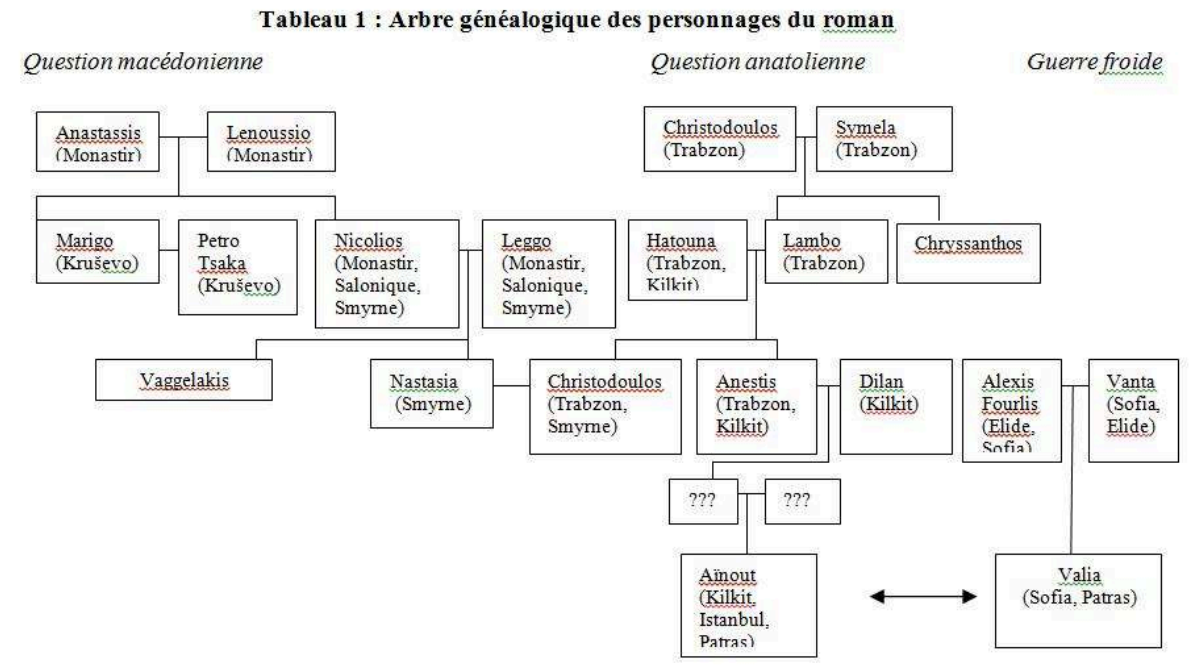

\section{NOTES}

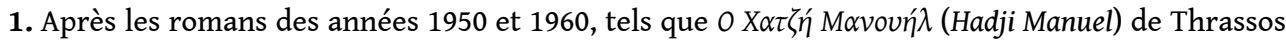

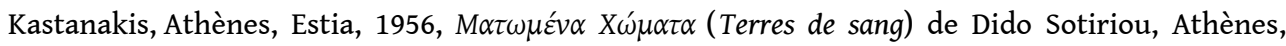
Kedros, 1962, $\Lambda \omega \xi \alpha$ v́v $\rho \alpha$ (Loxandra) de Maria Iordanidou, Athènes, Estia, 1963, on assiste à l'avènement d'une nouvelle génération de "romans ottomans » dans la littérature grecque, à

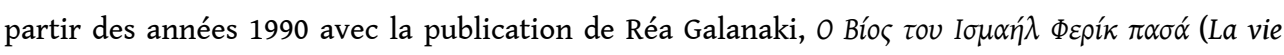

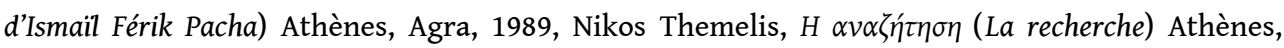

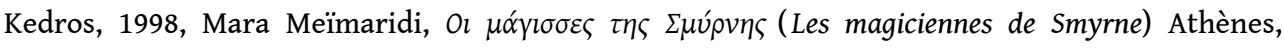




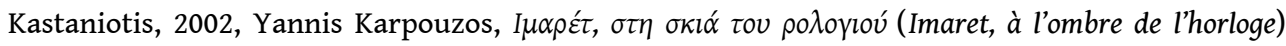
Athènes, Metehmio, 2008 (liste non exhaustive).

2. Il s'agit du troisième roman de cet écrivain né en 1951, à Patras.

3. Toi aussi, tu es Grec ?, Athènes, Kedros, 2005.

4. Voir Tableau 1.

5. Ce vilayet qui porte le nom de Bitola dans les langues slaves, constitue une des trois unités administratives composant la région géographique de la Macédoine ottomane, les deux autres étant, le vilayet de Salonique et une partie du vilayet de Kossovo.

6. Ce vilayet, se situant entre les côtes de la mer Noire et l'intérieur de l'Anatolie, fut au centre des revendications indépendantistes de la part de ses communautés roum et arménienne pendant la Grande Guerre.

7. La guerre civile grecque opposa entre 1943 et 1949 selon certains chercheurs, entre 1946-1949 selon d'autres, les partisans du parti communiste grec et ses sympathisants d'une part, aux forces royalistes, nationalistes et leurs alliés britanniques et américains d'autre part. À la fin de ce conflit, certains parmi les vaincus, c'est-à-dire les communistes et leurs adeptes subiront des persécutions et des exactions à l'intérieur de la Grèce, d'autres prendront le chemin de la fuite en se réfugiant dans des pays de l'Europe de l'Est et dans l'Union Soviétique.

8. La Question d'Orient renvoie à la série de crises diplomatiques et de conflits militaires qui jalonnent l'histoire de l'Empire ottoman tout au long du $\mathrm{XIX}^{\mathrm{e}}$ et au début du XX $\mathrm{XX}^{\mathrm{e}}$ siècles, aboutissant à sa disparition au lendemain de la Grande Guerre. Cette question des relations internationales se trouve à la croisée de deux phénomènes majeurs: d'une part, l'élaboration d'idéologies nationalistes au sein des domaines dirigés par le sultan et, d'autre part, l'expression de rivalités entre les grandes puissances en vue d'établir leur contrôle ou d'accroître leur influence sur l'Europe balkanique, la Méditerranée méridionale, l'Anatolie et le Moyen-Orient.

9. C'est la période pendant laquelle, des bandes armées soutenues par les royaumes de Bulgarie, de Grèce et de Serbie, se livrent une bataille acharnée pour la suprématie du territoire de la Macédoine ottomane.

10. Cet échange forcé de populations fut mené sur la base de critères confessionnels, et concerna les communautés musulmanes de la Grèce, à l'exception de celles de la région de la Thrace occidentale, et les communautés gréco-orthodoxes de la Turquie, à l'exception de celle d'Istanbul.

11. Dans l'historiographie française, cette thèse était déjà énoncée et diffusée, dans les années 1970, par des historiens comme Paul Veyne dans son ouvrage, Comment on écrit l'histoire. Essai d'épistémologie, Paris, Éditions du Seuil, 1971 et par des philosophes comme Paul Ricœur dans Temps et récit, Paris, Éditions du Seuil, 1983-5.

12. Lloyd Kramer, dans le chapitre 'Littérature, criticisme et imagination historique', publié dans l'ouvrage collectif dirigé par Lynn Hunt et intitulé The new cultural history, University of California Press, 1989, déclare qu'un des apports majeurs de cette nouvelle approche culturelle dans l'histoire « est l'influence du criticisme littéraire qui enseigna aux historiens de reconnaître le rôle actif du langage, des textes et des structures narratives dans la création et la description de la réalité historique » (pp. 97-98).

13. Cité dans l'ouvrage de Roger Chartier, Au bord de la falaise; l'histoire entre certitude et inquiétudes, Paris, Albin Michel, 1998, p. 102.

14. Voir Carlo Ginzburg, "Préface " à Lorenzo Valla, La donation de Constantin, texte traduit et commenté par J.-B. Giard, Paris, Les Belles Lettres, 1993, p. XI.

15. Michel de Certeau, «L'opération historiographique», dans L'Écriture de l'Histoire, Paris, Gallimard, 1975, pp. 63-120

16. Le millet est le regroupement des sujets du sultan sur des critères d'appartenance confessionnelle. Il s'agit d'une communauté religieuse reconnue par le pouvoir ottoman et qui, sous la responsabilité de son chef hiérarchique, s'auto-administre dans les domaines relevant de 
sa théologie et de sa morale, se conformant aux lois de l'Empire pour tout le reste. Il relève du millet tout ce qui concerne d'abord la religion, puis la famille, l'enseignement, la bienfaisance ; dans cette perspective, les autorités du millet sont également chargées de la mise en place et du financement des institutions nécessaires : tribunaux ecclésiastiques, écoles, hôpitaux et hospices.

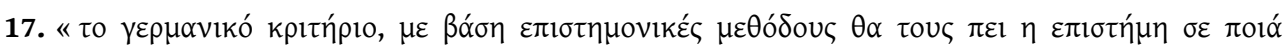

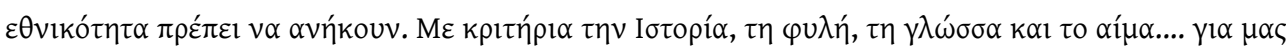

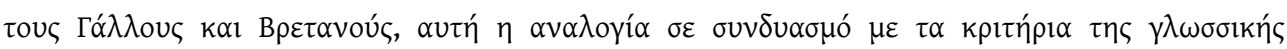

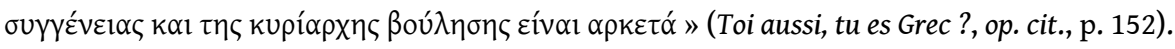

18. Pour une étude approfondie de l'approche plurielle de la notion de la nation, voir Hobsbawm Eric, Nations and nationalism since 1780, programme, myth, reality, Cambrige University Press, 1990.

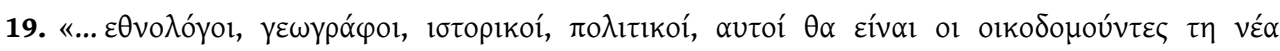

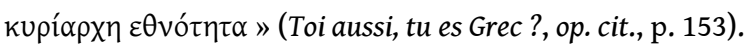

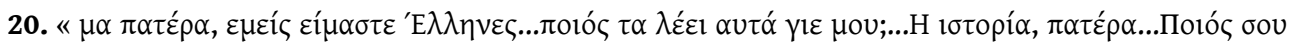

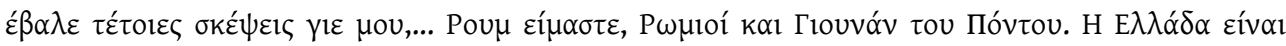

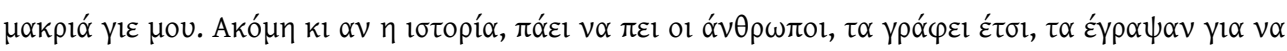
$\mu \alpha \varsigma \beta \alpha \sigma \alpha v i ́ \sigma o u v . »$ (Toi aussi, tu es Grec ?, op. cit., p. 79)

21. Un premier État bulgare vit le jour en 681. En 971, le basileus byzantin, Jean Tzimiscès vainquit l'armée du tsar Boris II, annexa la plus grande partie de son royaume et supprima le patriarcat bulgare créé par le tsar Siméon en 925. La création d'un nouveau royaume sous Samuel (976-1018) et la restauration du patriarcat d'Ohrid constituent des événements dont les Macédoniens actuels sont fiers, comme l'affirme Georges Castellan, dans son ouvrage, Un pays inconnu : La Macédoine hier et aujourd'hui, Crozon, éd. Armeline, 2003, p.20. En 1204, le tsar Kaloyan est couronné et son royaume persistera jusqu'en 1393. La constitution des royaumes slaves sur des territoires contrôlés par l'Empire byzantin et la reconnaissance de leur indépendance politique vis-à-vis du basileus fut suivie de leur affranchissement spirituel à l'égard du Patriarcat de Constantinople, avec l'établissement dans un premier temps d'un patriarcat à Ohrid, qui après 1018 et jusqu'en 1767 sera ramené au rang d'archevêché autocéphale, et ensuite d'un patriarcat à Tirnovo (1235-1393). La même évolution concerna également le royaume des Serbes avec la création d'un Patriarcat à Peć entre 1219 et 1459 et puis sa résurrection entre 1557 et 1756 pendant la période ottomane. Voir Robert Mantran, Histoire de l'Empire ottoman, Paris, Fayard, 1989, p.298 et p.320.

22. La création d'États-nations politiquement indépendants au détriment de l'Empire ottoman, pendant le temps de la Question d'Orient, fut accompagnée par la mise en place d'Églises autocéphales (le cas de la Grèce) ou des patriarcats autonomes (le cas de la Serbie, de la Bulgarie ou de la Roumanie)

23. Il faut savoir que l'usage des termes Grec, Hellène ou Roum donna lieu à une confusion sémantique considérable et leur emploi parallèle voire même interchangeable, sans aucun souci d'historicisation et de contextualisation entraîna, et provoque toujours, des amalgames et des anachronismes inouïs. Leur classification et distinction ne sont possibles qu'en tenant compte des différentes périodes historiques de leur usage ainsi que des différents points de vue de ceux qui les emploient. Dans cette optique, on constate que depuis l'époque de la romanisation politique de l'Empire romain, c'est-à-dire depuis l'attribution de la citoyenneté romaine à tous ses sujets suite au décret de Caracalla, tous ceux, qui se définissaient comme des Hellènes auparavant, vont progressivement se considérer comme des Romains. Dans ce sens, les sujets de l'Empire byzantin se sont toujours définis comme des Romains, d'autant plus que suite au processus de christianisation, le terme d'Hellène devient synonyme de païen. Cependant, cette appellation leur sera partiellement contestée par les observateurs extérieurs. Le pouvoir spirituel dans cet Empire, étant confié à l'institution du Patriarcat de Constantinople, sa langue liturgique étant le grec, tous les sujets byzantins dépendants de cette institution seront considérés comme des Grecs par les observateurs des royaumes chrétiens du reste de l'Europe centrale et 
occidentale. Cet amalgame était rendu possible non seulement pour des raisons linguistiques, mais également parce que la dualité du pouvoir temporel romain étant exclue par définition, à partir du moment où il $\mathrm{y}$ a eu un deuxième trône impérial revendiquant l'héritage romain, après le couronnement de Charlemagne, il était inconcevable que les sujets d'un autre empire puissent réclamer le même titre d'appellation. Par la suite, pendant la période ottomane, les sujets chrétiens de l'Empire ottoman rattachés au et contrôlés par le Patriarcat Roum d'Istanbul, seront regroupés dans le roum millet, et ce n'est qu'avec la création d'un État grec au XIX siècle que la question de la définition des habitants Roums de celui-ci va se poser. Parmi les trois propositions dominantes auprès des élites dirigeantes et savantes de ce nouvel État, Grec, Romios, ou Hellène (renvoyant au nom utilisé par une partie des grécophones de l'Antiquité pour désigner leur appartenance à une communauté culturelle), c'est la dernière qui l'a emporté. En même temps, les sujets chrétiens habitant dans des régions de l'Empire ottoman et dépendants, du point de vue de leur confession, du patriarcat d'Istanbul, continuaient à se considérer comme des Roums par eux-mêmes et par les autorités ottomanes, comme Grecs par les observateurs étrangers, et comme Hellènes par les nationalistes à l'intérieur et à l'extérieur de l'Empire. Il faut également préciser pour achever la complexité de ce tableau, que l'Empire ottoman et ensuite la République turque actuelle désignent sous le nom de Yunan les habitants de la Grèce, alors qu'ils appliquent toujours le terme des Roums à leurs citoyens chrétiens fidèles au Patriarcat grec-orthodoxe d'Istanbul.

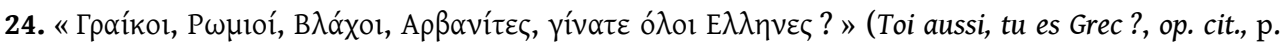
155).

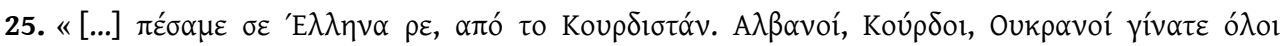

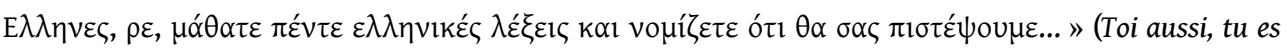
Grec ?, op. cit., p. 447).

26. Sur le contexte historique qui a vu la naissance du concept d'hellénisme au XIX ${ }^{\mathrm{e}}$ siècle, ainsi que pour ses significations politiques et ses récupérations idéologiques par les artisans de la mythologie nationale de l'État grec, voir Nikos Sigalas, «Hellénistes, hellénisme et idéologie nationale : de la formation du concept d'hellénisme en grec moderne » dans Chrissanthi Avlami (dir.), L'Antiquité grecque au XIXe siècle : un exemplum contesté ? Paris, L'Harmattan, 2000.

27. Voir Benedikt Anderson, Imagined communities, reflections on the origin and spread of nationalism, London, Verso, 1983.

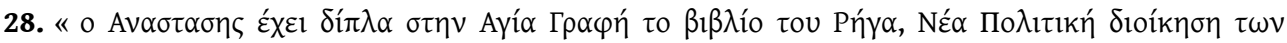

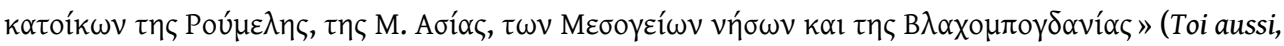
tu es Grec ?, op. cit., p. 29).

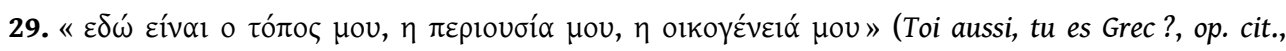
p. 318).

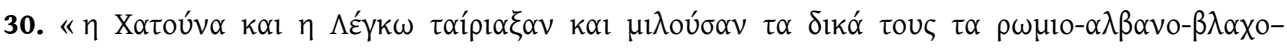
$\alpha \rho \mu \varepsilon ́ v ı k \alpha »$ (Toi aussi, tu es Grec ?, op. cit., p.294).

Il s'agit d'un phénomène avéré et relaté par les voyageurs étrangers qui se rendent dans la région tout au long du XIX ${ }^{\mathrm{e}}$ siècle. Pour une démonstration de ces témoignages, voir Mark Mazower, The Balkans, a short history, New York, Modern Library, 2002.

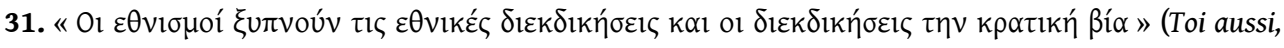
tu es Grec ?, op. cit., p. 265)

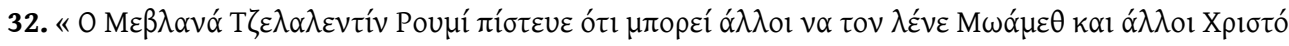

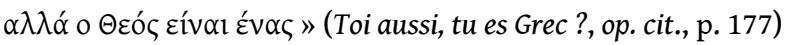

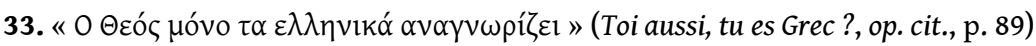

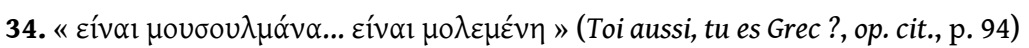

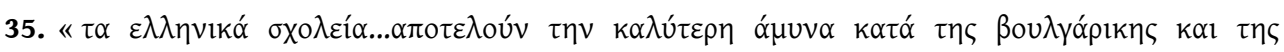

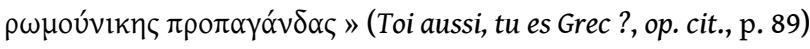




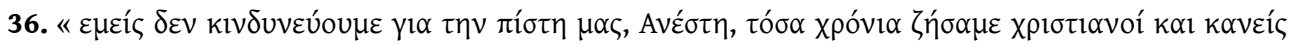

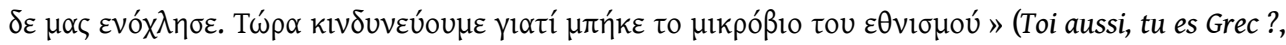
op. cit., p. 277)

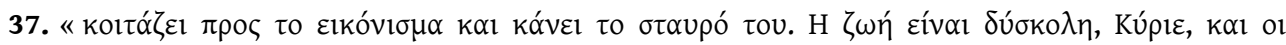

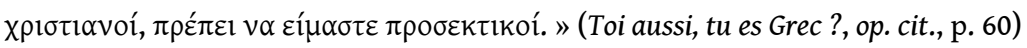

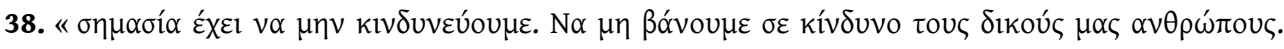

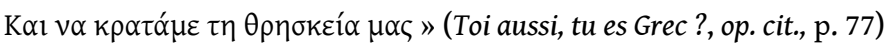

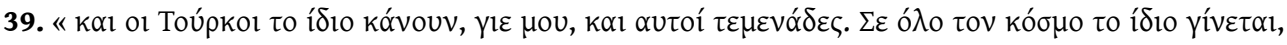

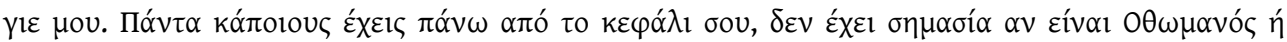

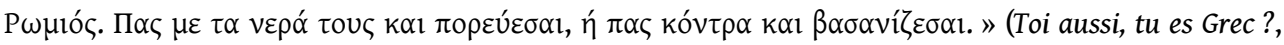
op. cit., p. 78)

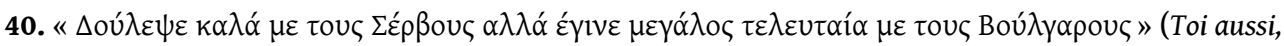
tu es Grec ?, op. cit., p. 230)

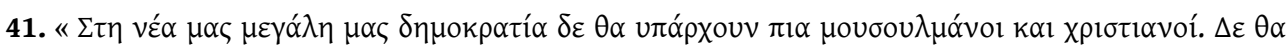

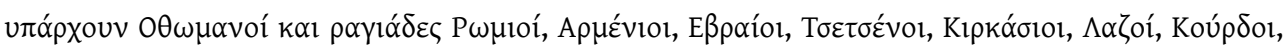

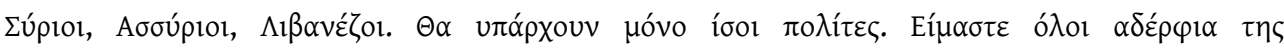

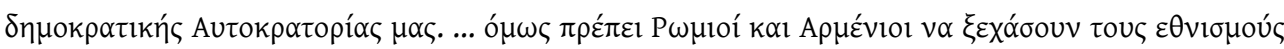

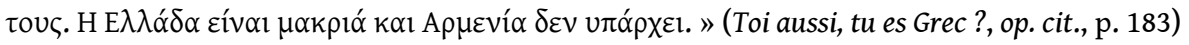

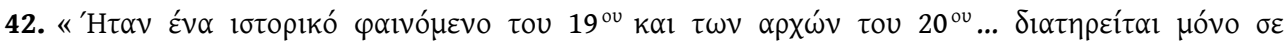

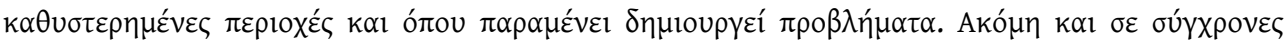

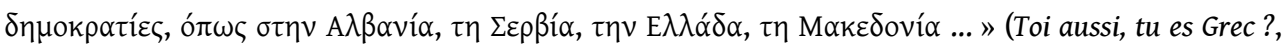
op. cit., p. 341).

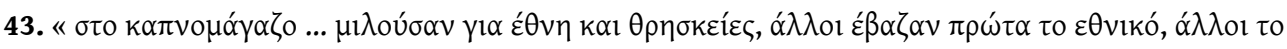

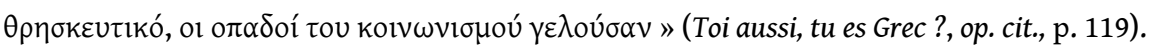

44. Sur les mouvements socialistes dans l'Empire ottoman et surtout dans la ville de Salonique, voir Paul Dumont, Du socialisme ottoman à l'internationalisme anatolien, Istanbul, Ed. Isis, 1997.

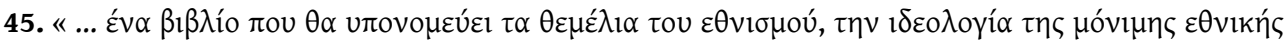

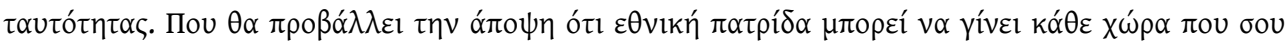

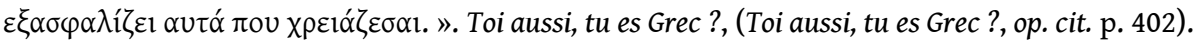

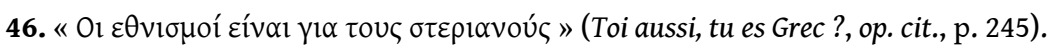

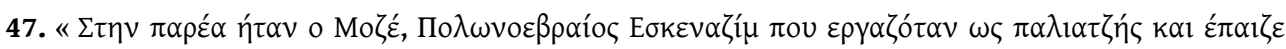

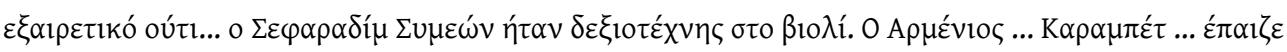

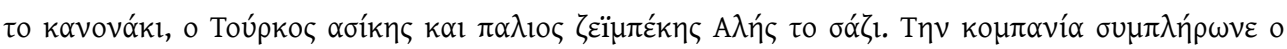

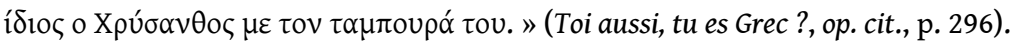

48. Voir Ernest Gellner, Nations and nationalism, Oxford, Blackwell, 1986.

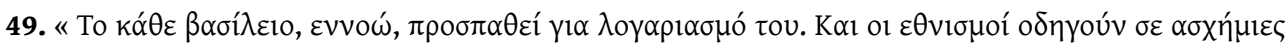

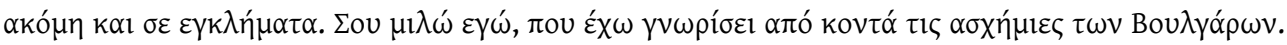

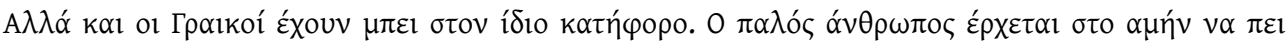

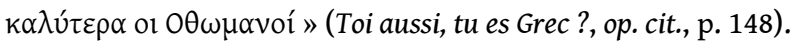

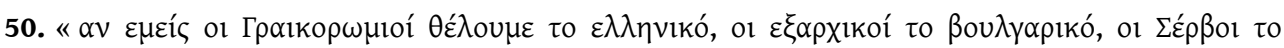

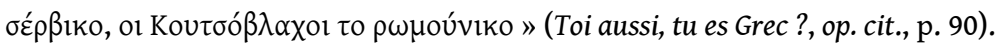

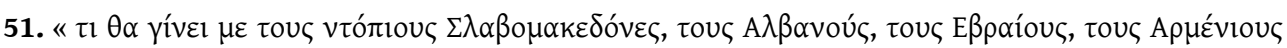

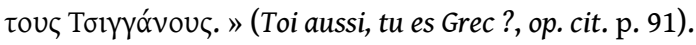

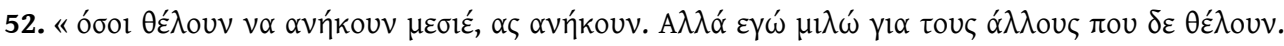

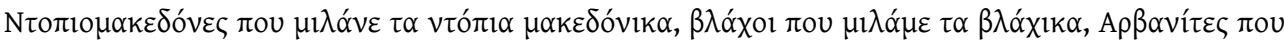

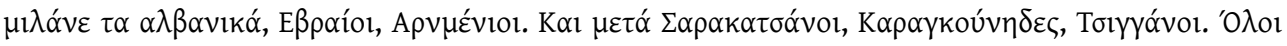

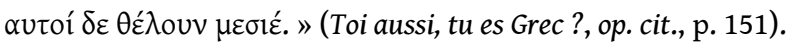

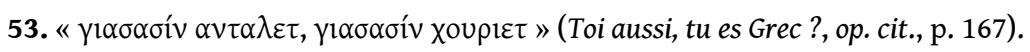




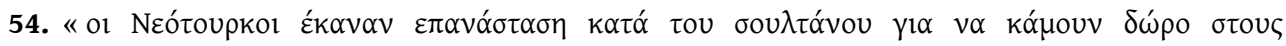

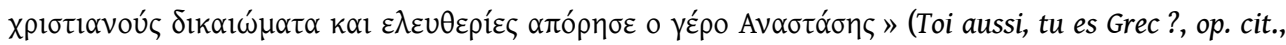
p. 175).

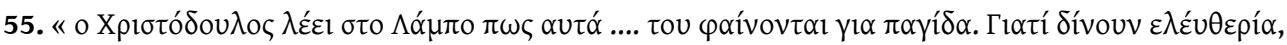

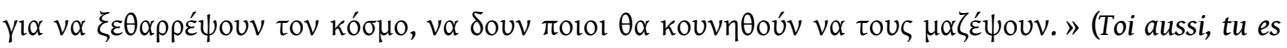
Grec ?, op. cit., p. 186).

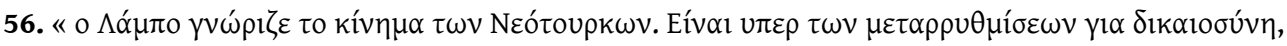

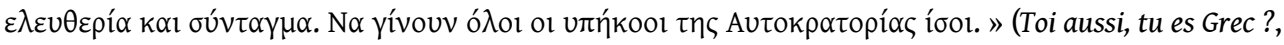
op. cit., p. 182).

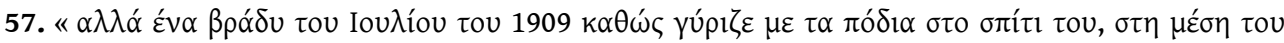

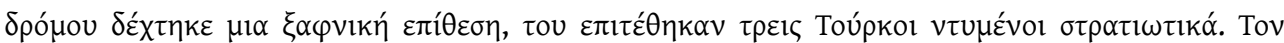

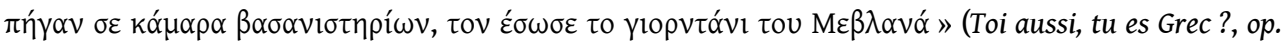
cit., p. 191).

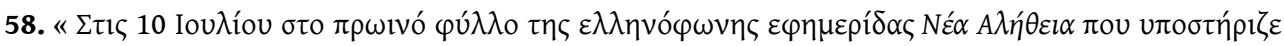

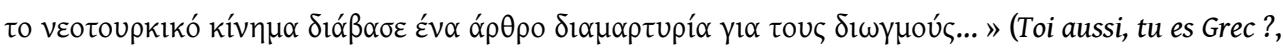
op. cit., p. 195).

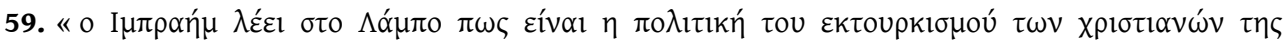

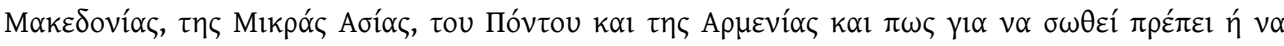

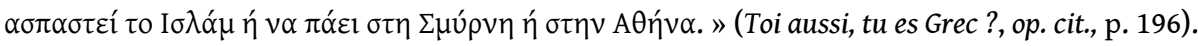

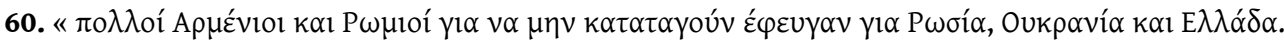

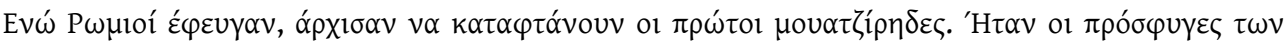
B $\alpha \lambda \kappa \alpha v i \kappa \omega ́ v \pi 0 \lambda \varepsilon ́ \mu \omega v . . . ~ »$ (Toi aussi, tu es Grec ?, op. cit., p. 209).

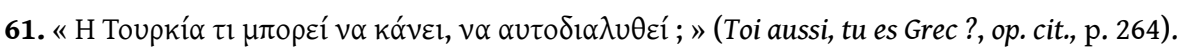

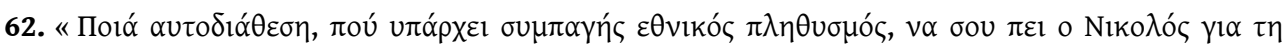

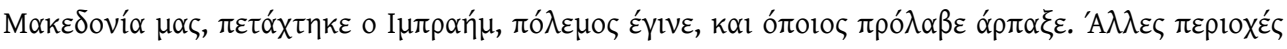

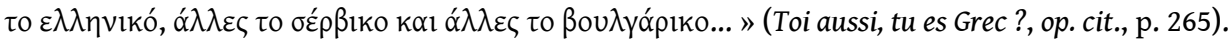

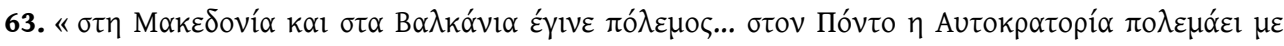

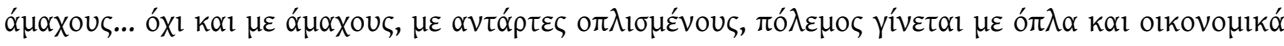

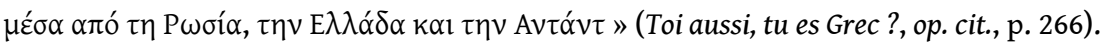

64. Voir Hayden White, "Historical emplotment and the problem of truth" in Probing the limits of representation, Nazism and the final solution, sous la direction de S. Friedlander, Cambridge, 1992, pp. 82-96.

65. Voir Toi aussi, tu es Grec ?, op. cit., p. 329).

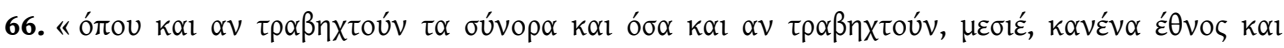

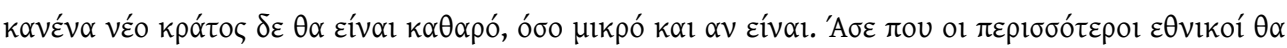

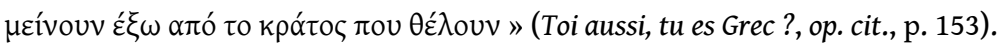

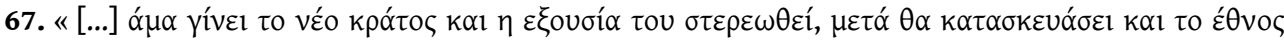

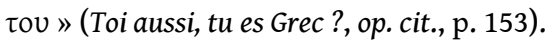

68. Anne-Marie Thiesse, «Les identités nationales, un paradigme transnational ", dans Alain Dieckhoff (dir.) Christophe Jaffrelot, Repenser le nationalisme, Paris, Sciences Po, 2006, pp. 196-197.

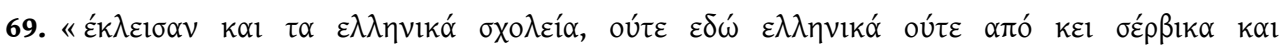

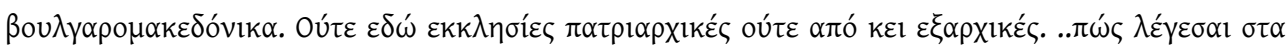

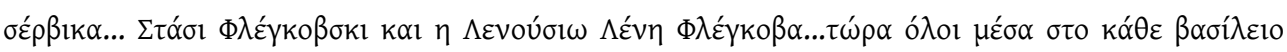

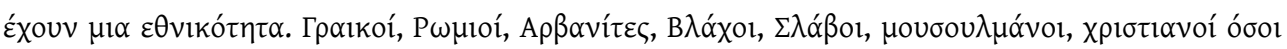

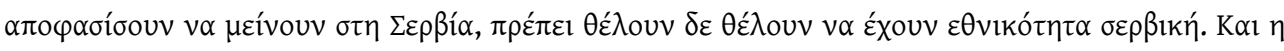

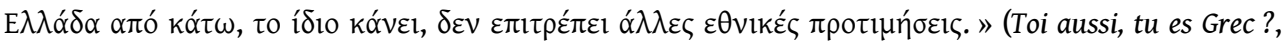
op. cit., p. 318 et p. 322).

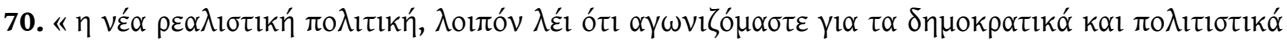

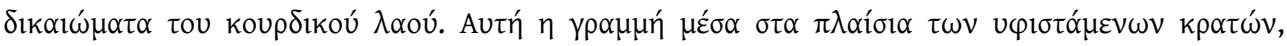




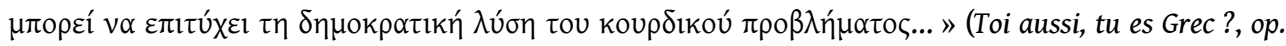
cit., p. 342).

71. «O

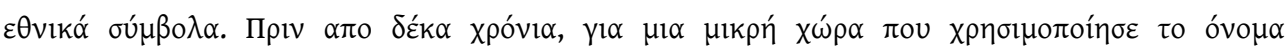

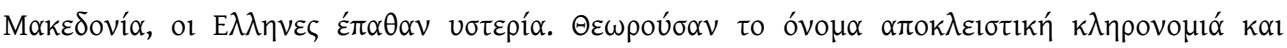

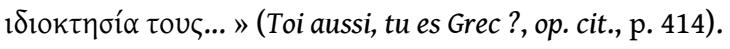

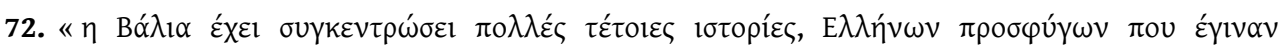

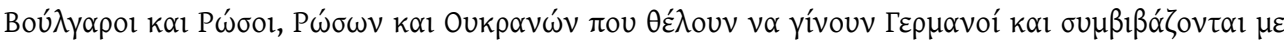

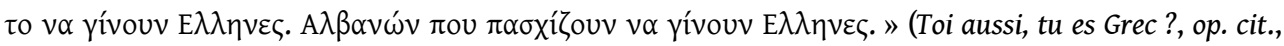
p. 402).

\section{RÉSUMÉS}

L'auteur de ce roman construit son intrigue sur l'histoire de plusieurs familles d'une part au moment de l'effondrement d'un monde, celui des millets de l'Empire ottoman fondé sur le principe de l'identification des individus en fonction de leurs croyances religieuses et, d'autre part, lors de la mise en place d'une nouvelle organisation politique, celle des États-nations obsédés par l'idée de la définition de l'individu sur la base de critères nationaux. L'exemple narratif dominant est celui du passage du millet des Roums à la nation des Grecs. Il s'agit d'un roman polyphonique quant à l'expression d'expériences traumatisantes issues de politiques de nettoyage ethnique et culturel, menées par les différentes parties impliquées dans les événements qui agitent l'Empire ottoman à la fin du XIX et au début du XX ${ }^{\mathrm{e}}$ siècle. Dans ce sens, l'écriture de ce roman s'oppose aux lectures exclusivistes de l'événement historique, largement diffusées par les mythologies nationales balkaniques visant à exalter les souffrances de nos compatriotes et de nos coreligionnaires, tout en effaçant ou occultant les destins tragiques des Autres.

The author of this novel puts in plot the history of various families, at the moment of the fall from one hand, of an entire world, this of ottoman empire's millets, based on the principle of individual identification following their religious beliefs and during the establishment on the other hand, of a new political organization, this of State-Nations, obsessed by the idea of individual definition on the basis of national criteria. The predominant narrative paradigm is this of the Roum millet transition towards the Greeks' nation. It is about a polyphonic novel, regarding to the expression of traumatic experiences issued by the ethnic and cultural cleansing policies, conducted by the different actors implicated in the events which stirred up trouble in the ottoman empire at the end of 19th and at the beginning of the 20th century. In this sense, the writing of this novel opposes itself to the exclusivist approaches of the historical event, largely spread across the national mythologies in Balkan countries, which are aiming at magnifying the sufferings of one's own compatriots or kin faith worshippers, while at the same time they erase or they minimize the tragic destinies of the Others. 
INDEX

Mots-clés : Amele taburu, Arvanite, Caza/Kaza, Karagounides, Koutzo-Valaque, Kruševo, Millet, Milletiste, Muhacir/mouhadjir, PKK, Roméika, Raïa/Raya/Reaya, Rum/Roum, Sarakatsanes, Tatavla, Valaque

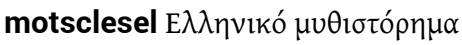

